\title{
Morphological and Molecular Identification of Penicillium islandicum Isolate KU101 from Stored Rice
}

\author{
Ji Yeon Oh${ }^{1}$, Eui Nam Kim ${ }^{1}$, Mun Il Ryoo ${ }^{2}$ and Ki Deok Kim ${ }^{1 *}$ \\ ${ }^{1}$ Division of Biotechnology, and ${ }^{2}$ Division of Environmental Science and Ecological Engineering, Korea University, Seoul 136- \\ 713, Korea \\ (Received on September 11, 2008; Accepted on November 6, 2008)
}

\begin{abstract}
We have previously obtained a representative isolate KU101 of the predominant Penicillium species from rice under indoor storage conditions. In this study we attempted to characterize isolate KU101 using its morphological and molecular characteristics. When the micro- and macroscopic characteristics of isolate KU101 were compared with the $P$. islandicum reference isolate KCCM 34763, isolate KU101 was generally identical to those of isolate KCCM 34763, however, isolate KU101 grew faster and produced more orange to red pigments than isolate KCCM 34763. In a molecular-based identification, the nuclear sequence of the ITS1-5.8S-ITS2 region of isolate KU101 was most closely related to that of $P$. islandicum. Therefore, these results indicated that isolate KU101 from stored rice could be identified as $P$. islandicum, some isolates of which are known to produce mycotoxins.
\end{abstract}

Keywords : identification, Penicillium islandicum, stored rice

Penicillium islandicum Sopp. is one of the most destructive and harmful fungi affecting rice in storage. In Korea, imported rice infected with $P$. islandicum was detected in 1973 (Kim et al., 1973). Park et al. (2005) also described the existence of $P$. islandicum in 15 out of 45 Korean polished rice samples. In Japan, Sakai et al. (2005) reported that three out of 100 samples of domestic rice harvested in 2001 and 2002 were contaminated with $P$. islandicum, and among the contaminated samples, $82 \%$ of rice grain in a sample was infected. The contamination of paddy and milled rice by $P$. islandicum also occurred in Argentina and Paraguay (Tonon et al., 1997).

In our previous study (Oh et al., 2007), we examined the populations of fungi and bacteria in stored rice from rice processing complexes of the National Agricultural Cooperative Federation of 11 regions in Korea and found that all rice samples were contaminated with Aspergillus and

\footnotetext{
*Corresponding author.

Phone) +82-2-3290-3065, FAX) +82-2-925-1970

E-mail)kidkim@korea.ac.kr
}

Penicillium spp. including a species examined in this study. Furthermore, we examined rice under controlled condition to monitor the temporal changes of fungal and bacterial population and diversity (Oh et al., 2008). Consequently, we found that various Penicillium spp. existed in stored rice and that changes in the conditions tested had little impact on the types of species occurred. However, the population of one (representative isolate KU101) of the most frequently appearing Penicillium species dramatically increased up to about $40-70 \%$ of total fungi in brown rice as the relative humidity was increased. Thus, the objective of this study was to identify the predominant species of Penicillium occurring in the stored rice using morphological and molecular characteristics.

A representative isolate KU101 of the predominant Penicillium species was obtained from rice samples in one ton bags being stored indoor condition at Korea University, Seoul, Korea in 2006. The morphological identification of isolate KU101 was conducted using eight different types of media and compared to the $P$. islandicum reference isolate KCCM 34763 from the Korean Culture Center of Microorganisms (KCCM), Seoul, Korea. The media used (Frisvad and Samson, 2004; Pitt and Hocking, 1999) were: 1) czapek yeast extract agar (CYA), 2) czapek yeast autolysate with 5\% $\mathrm{NaCl}$ (CYAS) agar, 3) czapek dox agar (CZ), 4) malt extract agar (MEA), 5) dichloran 18\% glycerol agar (DG18), 6) $25 \%$ glycerol nitrate agar $(\mathrm{G} 25 \mathrm{~N})$ to test the ability of isolate to grow at low $\mathrm{a}_{\mathrm{w}}, 7$ ) yeast extract sucrose agar (YES), and 8) creatine sucrose agar (CREA) which shows acid or base production by fungi. All media were placed at $25^{\circ} \mathrm{C}$ for 7 days when comparing the growth rates at different temperatures using CYAs incubated at 15, 25, and $30^{\circ} \mathrm{C}$. Colonies on each medium were compared for their diameters, overall colors, colors of conidia, reverse colors, and productions of sclerotia, exudates, and soluble pigments. Ehrlich reactions for detecting indole metabolites were conducted by the method of Lund (1995). Agar plugs (4 $\mathrm{mm}$ in diameter) from the center of a 7-day-old colony grown on CYA were cut and covered with discs $(1 \mathrm{~cm}$ in diameter) of Whatman filter paper (No. 1) wetted with Ehrlich reagent (4-dimethylaminobenzaldehyde 2 g, 96\% 
ethanol $85 \mathrm{ml}, 37 \%$ hycrochloric acid $15 \mathrm{ml})$. The reaction was observed 5 and $10 \mathrm{~min}$ after treatments. The fungal growth $(\mathrm{mm})$ on the media was determined with five plates (replications) and this experiment was repeated with similar results.

Microscopic features of isolates KU101 and KCCM 34763 on MEA, such as conidial heads, stipes, shapes of conidia, roughness of conidial walls, existence of ascospores or cleistothecia, lengths of phialides, and metulae, were determined using a microscope $(\times 1,000)$; these were compared with those of the $P$. islandicum described in the literature (Pitt, 2000). The branching patterns and appressedness of conidiophores were also observed to determines if they are mono-, bi-, or ter-verticillate and whether or not they are pressed close.

For molecular identification of isolate KU101, mycelial DNA was extracted from fungal cultures grown in potato dextrose broth at $28^{\circ} \mathrm{C}$ for 7 days. Extraction of DNA was conducted with the modified method of Boom et al. (1990). Polymerase chain reactions (PCRs) were performed using oligonucleotide primer pairs, ITS1 (5'-TCCGTAGGTGAACCTGCGG-3') and ITS4 (5'-TCCTCCGCTTATTGATATGC-3') (White et al., 1990), to amplify the nuclear ribosomal ITS1-5.8S-ITS2 region of Penicillium spp. The PCR contained the followings: $100 \mu \mathrm{l}$ of each reaction mixture containing template $10 \mu \mathrm{l}(10 \mathrm{ng} / \mu \mathrm{l})$, forward primer (ITS1) $10 \mu \mathrm{l}(20 \mathrm{ng} / \mu \mathrm{l})$, reverse primer (ITS4) $10 \mu \mathrm{l}(20 \mathrm{ng} /$ $\mu \mathrm{l}), 2.5 \mathrm{mM}$ dNTP $10 \mu \mathrm{l}, 10 \mathrm{x}$ reaction buffer $10 \mu \mathrm{l}$, Taq 1 $\mu \mathrm{l}$ (5 unit/ $\mu \mathrm{l})$, and distilled water $49 \mu \mathrm{l}$, and the cycling conditions were 1) an initial denaturation of $4 \mathrm{~min}$ at $95^{\circ} \mathrm{C}$, 2) 35 cycles of denaturation at $95^{\circ} \mathrm{C}$ for $30 \mathrm{~s}$, annealing at $52^{\circ} \mathrm{C}$ for $1 \mathrm{~min}$, and extension at $72^{\circ} \mathrm{C}$ for $1 \mathrm{~min}$, followed by 3) a final extension at $72^{\circ} \mathrm{C}$ for $7 \mathrm{~min}$. Following amplification, the PCR products were run on gels composed of $1.5 \%(\mathrm{w} / \mathrm{v})$ agarose (Roche Diagnostics, Indianapolis, USA) in TAE buffer [0.045 M Tris, $0.089 \mathrm{M}$ boric acid, $0.002 \mathrm{M}$ EDTA (pH 8.4)] at $100 \mathrm{~V}$ for 120 to $150 \mathrm{~min}$. The sequences of the ITS1-5.8S-ITS2 region of closely-related type strains of Penicillium species were obtained by Blast analysis against the GenBank DNA databases. Multiple sequence alignments were carried out using the ClustalX multiple sequence alignment program (European Molecular Biology Laboratory, Heidelberg, Germany). Phylogenetic and molecular evolutionary analyses were conducted using the Molecular Evolutionary Genetics Analysis (MEGA) version 3.1 program (The Biodesign Institute, Tempe, USA). The 16S rDNA sequence of isolate KU101 has been deposited in GenBank under accession number FJ197220.

Colonies of isolate KU101 on CYA at 25 and $30^{\circ} \mathrm{C}$ were slightly sulcate, centrally rose, and velutinous to lightly floccose (Fig. 1A). Diameters of the colonies on CYA were, on average, $10.7 \mathrm{~mm}$ at $15^{\circ} \mathrm{C}, 23.9 \mathrm{~mm}$ at $25^{\circ} \mathrm{C}$, and 30.2 $\mathrm{mm}$ at $30^{\circ} \mathrm{C}$. Colors of mycelia on CYA were deep orange covering the central part of colony and grayish turquoise on the conidia especially in the margin of a colony. Conidiogenesis was moderate and usually covered with orange to red-brown mycelia. Sometimes clear to pale yellow exudates were produced. Colonies on CYAS were, on average, $22.9 \mathrm{~mm}$ in diameter and similar to those on CYA except that their mycelia were deep orange. Colonies on $\mathrm{CZ}$ were, on average, $19.9 \mathrm{~mm}$ in diameter and slightly sulcate. Their mycelia were yellow, conidia grayish green, and conidiogenesis was moderate. The reverse colors on CYA, CYAS, and $\mathrm{CZ}$ were strongly pigmented with an orangish brown to

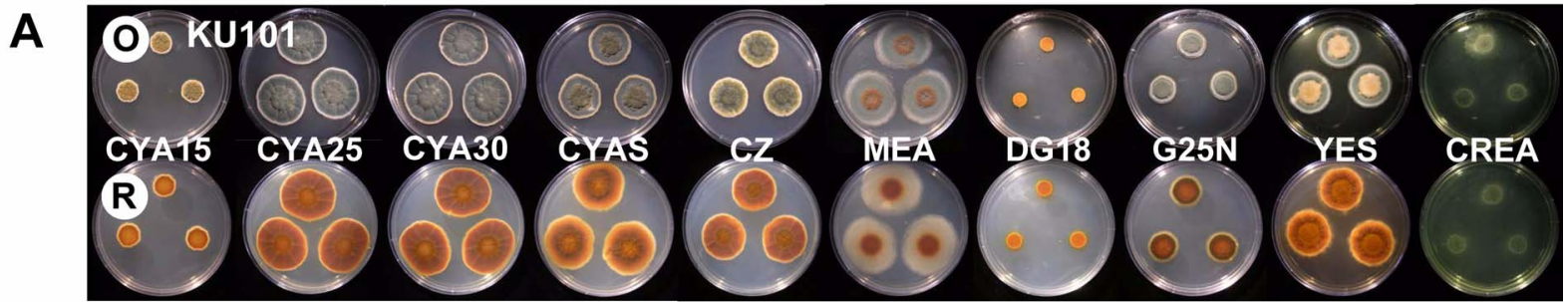

B

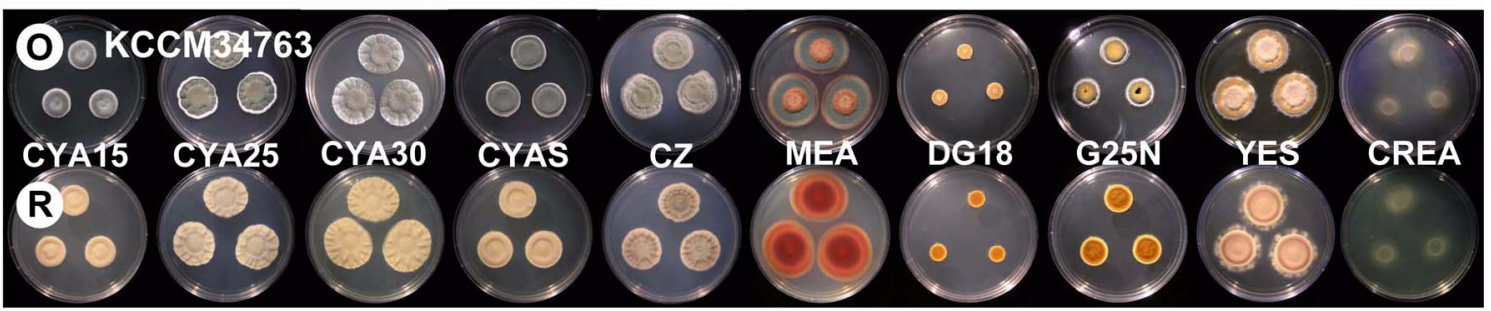

Fig. 1. Morphologies of (A) the Penicillium islandicum isolate KU101 and (B) the P. islandicum reference isolate KCCM 34763 on different media such as czapek yeast extract agar grown at $15^{\circ} \mathrm{C}(\mathrm{CYA} 15), \mathrm{CYA}$ at $25^{\circ} \mathrm{C}(\mathrm{CYA}), \mathrm{CYA}$ at $30^{\circ} \mathrm{C}(\mathrm{CYA} 30)$, czapek yeast extract agar with $5 \% \mathrm{NaCl}$ (CYAS), czapek dox agar (CZ), malt extract agar (MEA), dichloran 18\% glycerol agar (DG18), 25\% glycerol nitrate agar $(\mathrm{G} 25 \mathrm{~N})$, yeast extract sucrose agar (YES), and creatine sucrose agar (CREA) at $25^{\circ} \mathrm{C}$. O, obverse of the culture plate; R, Reverse. 
Table 1. Quantitative and qualitative characteristics of Penicillium islandicum isolates KU101 and KCCM 34763 in comparison with characteristics described by Pitt (2000)

\begin{tabular}{|c|c|c|c|c|}
\hline \multicolumn{2}{|c|}{ Characteristics } & $\begin{array}{l}\text { Present isolate } \\
\text { KU101 }\end{array}$ & $\begin{array}{c}\text { Reference isolate } \\
\text { KCCM } 34763\end{array}$ & Pitt (2000) \\
\hline \multicolumn{5}{|l|}{ Quantitative characters } \\
\hline \multirow{11}{*}{$\begin{array}{l}\text { Microscopical } \\
\text { features }^{\mathrm{a}}\end{array}$} & Conidia $^{\mathrm{b}}$ & & & \\
\hline & Shape & $\begin{array}{l}\text { Globose to } \\
\text { subspheroidal }\end{array}$ & $\begin{array}{l}\text { Globose to } \\
\text { subspheroidal }\end{array}$ & $\begin{array}{l}\text { Ellipsoidal to } \\
\text { subspheroidal }\end{array}$ \\
\hline & Length & $2.4-3.5 \mu \mathrm{m}$ & $2.6-3.7 \mu \mathrm{m}$ & $3.0-3.5 \mu \mathrm{m}$ \\
\hline & Roughness & Smooth & Smooth & Smooth \\
\hline & Phialide length $^{\mathrm{c}}$ & $7-9 \mu \mathrm{m}$ & $8-10 \mu \mathrm{m}$ & $7-8 \mu \mathrm{m}$ \\
\hline & $\begin{array}{l}\text { Metulae length } \\
\text { Stipe }\end{array}$ & $9-11 \mu \mathrm{m}$ & $9-11 \mu \mathrm{m}$ & $8-10 \mu \mathrm{m}$ \\
\hline & Length & $23-48 \mu \mathrm{m}$ & $29-44 \mu \mathrm{m}$ & $30-60 \mu \mathrm{m}$ \\
\hline & Roughness & Smooth & Smooth & Smooth \\
\hline & Conidiophore & & & \\
\hline & Branching pattern & $\begin{array}{c}\text { Mono-verticillate, } \\
\text { Bi-verticillate }\end{array}$ & $\begin{array}{c}\text { Mono-verticillate, } \\
\text { Bi-verticillate }\end{array}$ & Bi-verticillate \\
\hline & Appressedness & Appressed & Appressed & Appressed \\
\hline \multirow{3}{*}{$\begin{array}{l}\text { Ecophysiological } \\
\text { characteristics }\end{array}$} & CYA30 / CYA25 & 1.44 & 1.92 & $--^{\mathrm{e}}$ \\
\hline & CYA15 / CYA25 & 0.45 & 0.57 & - \\
\hline & CYAS25 / CYA25 & 2.14 & 1.89 & - \\
\hline Ehrlich reaction & & $\begin{array}{c}\text { No reaction } \\
\text { or yellow }\end{array}$ & $\begin{array}{l}\text { No reaction } \\
\text { or yellow }\end{array}$ & - \\
\hline \multicolumn{5}{|l|}{ Qualitative characters } \\
\hline \multirow{2}{*}{$\begin{array}{l}\text { Reaction on } \\
\text { Creatine sucrose agar }\end{array}$} & Acid production & Huge & Moderate & - \\
\hline & Base production & None & None & - \\
\hline
\end{tabular}

${ }^{a}$ Features such as lengths of each part of conidia and conidiophores were determined using a microscope $(\times 1,000)$.

${ }^{\mathrm{b}}$ Lengths of conidia were determined with 50 observations.

${ }^{\mathrm{c}}$ Lengths of phialide, metulae, and stipe were determined with 20 observations.

${ }^{\mathrm{d}}$ Ratios of the diameter of fungal colonies on czapek yeast extract agar (CYA) media grown at 30,25 , and $15^{\circ} \mathrm{C}$ and czapek yeast extract sucrose agar with $5 \% \mathrm{NaCl}$ (CYAS) grown at $25^{\circ} \mathrm{C}$.

${ }^{\mathrm{e}}$ Not described.

red color. On MEA, colony diameter were, on average, 29.0 $\mathrm{mm}$ granular and plane. Mycelia were deep orange and less dominant, conidia were dull, grayish blue and conidiogenesis was heavy. The reverse color of central colonies was strongly pigmented-reddish brown and the margin was white. Colonies growing on DG18 were, on average, 10.0 $\mathrm{mm}$ and conidiogenesis was absent to weak, and the reverse color was orange. Colonies on G25N were, on average, $17.1 \mathrm{~mm}$ and similar in appearance and coloration to those on CYA except they were less sulcate. The reverse color was orange to brown. Colonies on YES were, on average, $28.6 \mathrm{~mm}$ and similar in appearance to those on G25N, except that they were sulcate and the mycelia were more dominant. The YES reverse color was also similar to that of G25N but brighter. Colonies on CREA were, on average, $25.3 \mathrm{~mm}$ in diameter and plane. Conidiogenesis was weak and acid production huge.

Overall, the described morphological characteristics of isolate KU101 on the media mentioned were identical to those of the P. islandicum reference isolate KCCM 34763 (Fig. 1B). Colony diameters of the isolate KU101 were usually greater than those of reference isolate KCCM 34763 except when grown on CYA at $15^{\circ} \mathrm{C}$ and $\mathrm{G} 25 \mathrm{~N}$. Isolate KU101 showed stronger conidiogenesis than reference isolate KCCM 34763 , especially when compared to colonies of reference isolate KCCM 34763 on YES and G25N which were covered with pale yellow to orange-colored mycelium and showed weak sporulation. The erhlich reactions between the two isolates were similar, however, acid production of isolate KU101 on CREA was stronger than that of the reference isolate KCCM 34763. Also, isolate KU101 tended to produce more orange-colored pigment on the reverse side of the colonies than isolate KCCM 34763. Many researchers reported that the coloring components and toxins of $P$. islandicum were anthraquinones (Kawai et al., 1984), skyrins (Kawai et al., 1986), cyclochlotine, hydroxycyclochlorotine, and islanditoxin (Mizutani et al., 2008). Anthraquinones and skyrins, the red pigments, are 


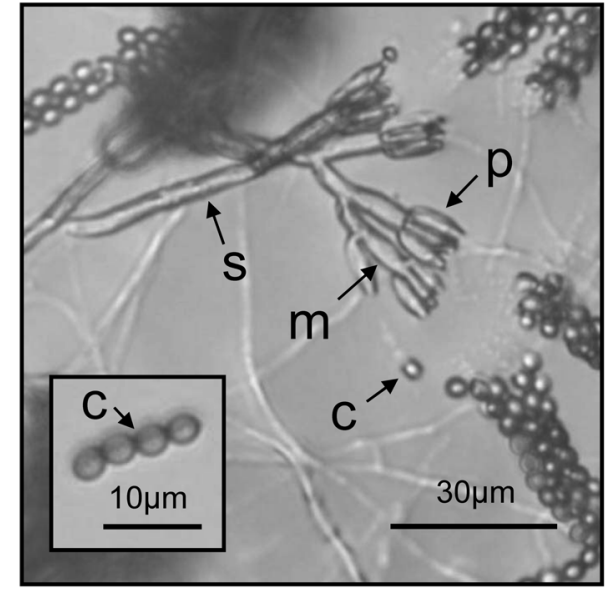

Fig. 2. A microscopic observation $(\times 1,000)$ of conidiophores and conidia (close-up in the internal box) of the Penicillium islandicum isolate KU101. c, conidia; m, metulae; $\mathrm{p}$, phialides; s, stipes of conidiophore.

liver and kidney toxins and carcinogens (Kobayashi et al., 1958).

The microscopic characteristics of isolate KU101 also were similar to those of reference isolate KCCM 34763 and explained by Pitt (2000). Conidiophores of isolate KU101 were borne from aerial hyphae, and the length of stipe was 23-48 $\mu \mathrm{m}$ with smooth walls while those described by Pitt (2000) were 30-60 $\mu \mathrm{m}$ with smooth walls (Table 1 and Fig. 2). Branching patterns of penicilli were terminal and mono-, bi-verticillate, while Pitt (2000) recorded them as biverticillate. The length of metulae averaged $8 \mu \mathrm{m}$ and were appressed in accordance with the observation of Pitt (2000). The length of phialides was usually $7-9 \mu \mathrm{m}$ for isolate KU101 while 7-8 $\mu \mathrm{m}$ in the literature (Pitt, 2000). The isolate KU101 had globose to subspheroidal and 2.4-3.5 $\mu \mathrm{m}$-long conidia born in short columns with smooth walls. Pitt (2000) also described conidia to be smooth-walled, but ellipsoidal to subspheroidal and 3.0-3.5 $\mu \mathrm{m}$ in length (Table 1 and Fig. 2). Characteristics of isolate KU101 were also similar to those of reference isolate KCCM 34763 in the shapes and lengths of conidia (2.6-3.7 $\mu \mathrm{m}$, globose to subspheroidal, smooth-walled), phialides $(8-10 \mu \mathrm{m})$, metulae (9-11 $\mu \mathrm{m})$, stipe (29-44 $\mu \mathrm{m}$, smooth-walled), and branching pattern (mono- and bi-verticillate) (Table 1). A neighborjoining tree of Penicillium species related with $P$. islandicum based on phylogenetic analysis of the ITS1-5.8S-ITS2 region showed that the isolate KU101 was distinct from other Penicillium spp. while most closely related (98\%) with databases of $P$. islandicum isolates on the National Center for Biotechnology Information (NCBI) (Fig. 3). Taken together, these results indicated that the isolate KU101 from stored rice could be identified as $P$. islandicum, some isolates of which are known to produce mycotoxins.

\section{Acknowledgment}

This study was carried out with the support of "Specific Joint Agricultural Research-Promoting Projects (Project No. 20070101-033-025-001-03-00)", RDA, Republic of Korea.

\section{References}

Boom, R., Sol, C. J. A., Salimans, M. M. M., Jansen, C. L., Wertheim-Van Dillen, P. M. E. and Van Der Noordaa, J. 1990. Rapid and simple method for purification of nucleic acids. $J$.

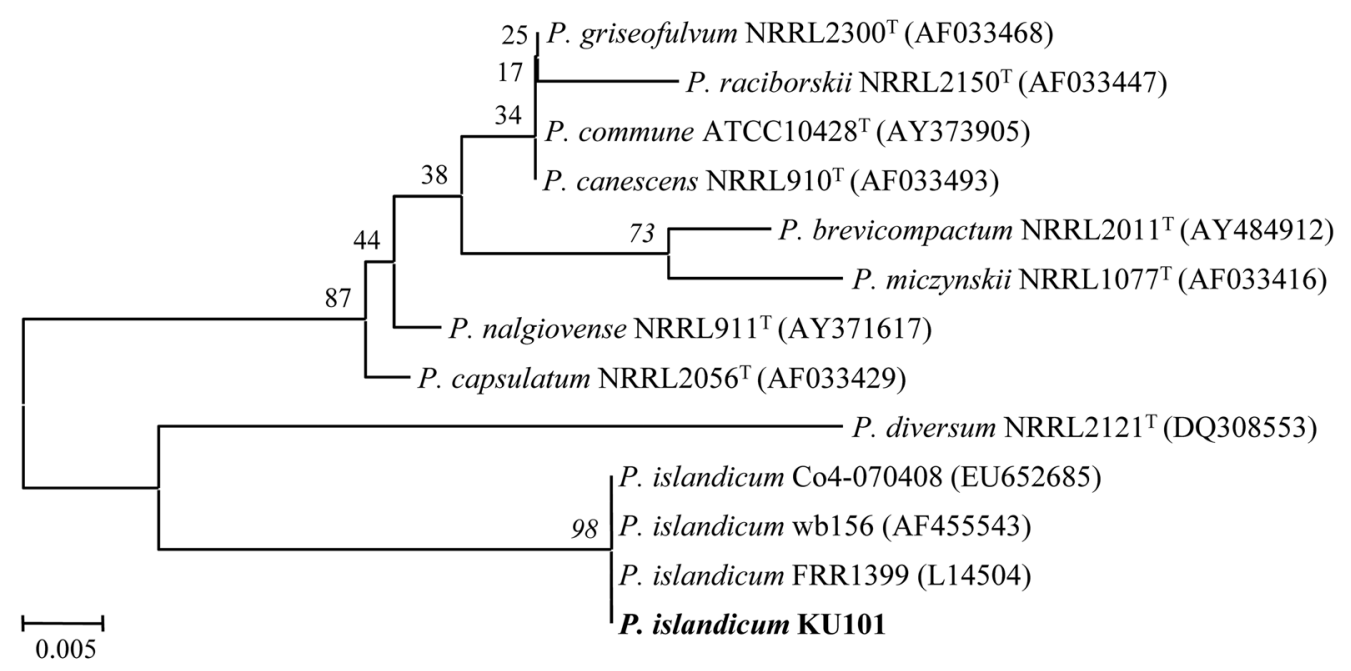

Fig. 3. A neighbor-joining tree of the Penicillium species relative to the Penicillium islandicum isolate KU101 based on phylogenetic analysis of the nuclear ribosomal ITS1-5.8S-ITS2 region sequences. Bootstrap values of 100 analyses are shown at the branching point. The type strain of the species and accession numbers are indicated as " $\mathrm{T}$ " and in parentheses, respectively. 
Clin. Microbiol 28:495-503.

Frisvad, J. C. and Samson, R. A. 2004. Polyphasic taxonomy of Penicillium subgenus Penicillium. A guide to identification of food and air-borne terverticillate Penicillia and their mycotoxins. Studies in Mycology 49:1-174.

Kawai, K., Kato, T., Moric, H., Kitamura, J. and Nozawa, Y. 1984. A comparative study on cytotoxicities and biochemical properties of anthraquinone mycotoxins emodin and skyrin from Penicillium islandicum Sopp. Toxicol. Lett. 20:155-160.

Kawai, K., Nozawa, Y., Morl, H. and Ogiharac, Y. 1986. Inhibition of mitochondrial respiration by flavoskyrin, a toxic metabolite of Penicillium islandicum Sopp. Toxicol. Lett. 30: 105-111.

Kim, Y. B. and Cho, D. H. 1973. Types of deterioration of storage rice in Korea and identification of the causative microorganisms (II). J. Kor. Agric. Chem. Soc. 17:54-62.

Kobayashi, Y., Uraguchi, K., Tatsuno, T., Sakai, F., Tsukioka, M., Sakai, Y., Yonemitsu, O. and Sato, T. 1958. Toxicological studies on the yellowed rice by P. islandicum Sopp. II. Isolation of the two toxic substances from the noxious fungus, and their chemical and biological properties. Proc. Jpn. Acad. 34: 736-741.

Lund, F. 1995. Differentiating Penicillium species by detection of indole metabolites using a filter paper method. Lett. Appl. Microbiol. 20:228-231.

Mizutani, K., Hirasawa, Y., Sugita-Konishi, Y., Mochizuki, N. and Morita, H. 2008. Structural and conformational analysis of hydroxycyclochlorotine and cyclochlorotine, chlorinated cyclic peptides from Penicillium islandicum. J. Nat. Prod. 71: 1297-1300.
Oh, J. Y., Jee, S. N., Nam, Y., Lee, H., Ryoo, M. I. and Kim, K. D. 2007. Populations of fungi and bacteria associated with samples of stored rice in Korea. Mycobiology 35:36-38.

Oh, J. Y., Sang, M. K., Lee, S. Y., Ryoo, M. I. and Kim, K. D. 2008. Temporal changes of fungal and bacterial populations in rice under indoor storage conditions. Plant Pathol. J. 24:7479.

Park, J. W., Choi, S., Hwang, H. and Kim, Y. 2005. Fungal mycoflora and mycotoxins in Korean polished rice destined for humans. Int. J. Food Microbiol. 103:305-314.

Pitt, J. I. 2000. A laboratory guide to common Penicillium species. 3rd ed. Food Science Australia, North Ryde, Australia. $197 \mathrm{pp}$.

Pitt, J. I. and Hocking, A. D. 1999. Fungi and food spoilage. 2nd ed. Aspen Publications, Gaithersburg, USA. 413pp.

Sakai, A., Tanaka, H., Konishi, Y., Hanazawa, R., Ota, T., Nakahara, Y., Sekiguchi, S., Oshida, E., Takino, M., Ichinoe, M., Yoshikawa, K., Yoshizawa, T. and Takatori, K. 2005. Mycological examination of domestic unpolished rice and mycotoxin production by isolated Penicillium islandicum. J. Food Hyg. Soc. Japan 46:205-212.

Tonon, S. A., Marucci, R. S., Jerke, G. and García, A. 1997. Mycoflora of paddy and milled rice produced in the region of northeastern Argentina and southern Paraguay. Int. J. Food Microbiol. 37:231-235.

White, T. J., Bruns, T., Lee, S. and Tayor, J. W. 1990. Amplification and direct sequencing of fungal ribosomal RNA genes for phylogenetics. In: PCR Protocols: A Guide to Methods and Applications, ed. by M. A. Innis, D. H. Gelfand, J. J. Sninsky and T. J. White, pp. 315-322. Academic Press, Inc., New York. 